\title{
Lung Sarcoma
}

National Cancer Institute

\section{Source}

National Cancer Institute. Lung Sarcoma. NCI Thesaurus. Code C4860.

A malignant mesenchymal neoplasm that arises from the lung. Representative examples include Kaposi sarcoma, leiomyosarcoma, and synovial sarcoma. 